\title{
Genotype $\times$ Environment Interaction of Mosaic Disease, Root Yields and Total Carotene Concentration of Yellow-Fleshed Cassava in Nigeria
}

\author{
Norbert G. Maroya, ${ }^{1}$ Peter Kulakow, ${ }^{1}$ Alfred G. O. Dixon, ${ }^{2}$ and Busie B. Maziya-Dixon' \\ ${ }^{1}$ International Institute of Tropical Agriculture, Cassava Breeding Program, PMB, Oyo State, Ibadan 5320, Nigeria \\ ${ }^{2}$ Sierra Leone Agricultural Research Institute, General Directorate, PMB, Freetown 1313, Sierra Leone \\ Correspondence should be addressed to Norbert G. Maroya, n.maroya@cgiar.org
}

Received 3 February 2012; Revised 27 April 2012; Accepted 11 May 2012

Academic Editor: Robert J. Kremer

Copyright (C) 2012 Norbert G. Maroya et al. This is an open access article distributed under the Creative Commons Attribution License, which permits unrestricted use, distribution, and reproduction in any medium, provided the original work is properly cited.

\begin{abstract}
Twenty-one yellow-fleshed cassava genotypes were evaluated over two years in five major cassava growing agroecological zones in Nigeria. The trials were established in a randomized complete block design with four replications to assess genotype performance and Genotype $\times$ Environment interaction for cassava mosaic disease (CMD), fresh and dry root yield (FYLD; DYLD), root dry matter content (DMC), and total carotene concentration (TCC). Combined analysis of variance showed significant differences $(P<0.001)$ among genotypes $(\mathrm{G})$, environment $(\mathrm{E})$, and Genotype $\times$ Environment interaction $(\mathrm{GE})$ for all the traits tested. For reaction to CMD, the best genotypes showing stable resistance were TMS 07/0539 and TMS 07/0628. For root yield, the best genotypes were TMS 01/1368 and TMS 07/0553. Genotype TMS 07/0593 was the best for DMC and TCC across the 10 environments. Variation among genotypes accounted for most of the Total Sum of Squares for CMD (72.1\%) and TCC (34.4\%). Environmental variation accounted for most of the Total Sum of Squares for FYLD (42.8\%), DYLD (39.6\%), and DMC (29.2\%). This study revealed that TMS 07/0593 has the highest and most stable TCC, DMC with the lowest CMD severity score and appeared to be the best genotype.
\end{abstract}

\section{Introduction}

Vitamin A deficiency (VAD) is a global problem of public health significance in under-privileged communities of the world [1]. Xerophthalmia is the most readily recognized and the most widely employed criterion for discussing whether VAD poses a significant public health problem in any particular community [2]. Vitamin A deficiency in the early stage leads to night blindness and Xerophthalmia, which may ultimately progress to blindness [3]. A nationwide food consumption and nutrition survey conducted in Nigeria revealed that $29.5 \%$ of children under 5 years of age were vitamin A deficient (serum retinol $<0.70 \mu \mathrm{mol} / \mathrm{L}$ ) [4]. Cassava (Manihot esculenta Crantz) is an important food security crop and a major source of calories for about two of every five Africans [5]. Although the starchy root is the primary product, fresh leaves are also used for animal and/or human consumption [6]. In 2008, Nigeria was the leading cassava producing country in sub-Saharan Africa, producing 44.6 million tons on 3.8 million ha [7]. In Nigeria, more than $70 \%$ of cassava production is processed at the village level into gari, the principal source of calories for 70-80 million Nigerians. Cassava varieties often demonstrate specific adaptation due to their high sensitivity to the genotype-by-environment interaction $(\mathrm{G} \times \mathrm{E})$ that occurs in both short-term and long-term crop performance trials [8] and is a major concern in plant breeding because it reduces progress from selection. This makes cultivar recommendation difficult because the choice of superior cultivars changes with locations [9].

$\beta$-carotene is the most potent and widespread form of pro-vitamin A [10] and is the predominant carotenoid in cassava, occurring as a mixture of 13 -cis- $\beta$-carotene; trans$\beta$-carotene and 9-cis- $\beta$-carotene forms [11]. Because the 
cis-isomers are known to have lower vitamin A activity and are present in insignificant levels compared with the transform, the quantitative method should determine the trans and the cis-isomers individually. However, this makes the analysis more expensive and complicated. An earlier study in cassava [12] revealed in $\left(0.1-3 \mathrm{mg} \mathrm{kg}^{-1}\right.$ Fresh Weight) of $\beta$-carotene and $\left(0.05-0.6 \mathrm{mg} \mathrm{kg}^{-1} \mathrm{FW}\right)$ of lutein. Other carotenoids present in cassava roots but in very small amount included $\alpha$ - $\gamma$ - and $\zeta$-carotene and $\beta$-cryptoxanthin [12]. In Brazil, one the cassava clone (UnB 500) which has been grown by indigenous farmers and available at the University of Brasilia gene bank showed a high lycopene content. Lycopene was shown to be the major carotenoid, although $\alpha$-carotene and cis-lycopene were also found [13]. In the same study, another clone (UnB 400) analyzed for carotenoids showed trans- $\beta$-carotene reached $27.40 \mu \mathrm{g} / \mathrm{g}$. Trans- $\beta$-carotene acts as an antioxidant that helps to prevent heart attacks and cancer, lowers cataract risks and muscular disorders, and enhances the immune system [14]. $\beta$-carotene is also required for growth, reproduction, vision and the maintenance of the integrity of epithelial tissue. Structurally, vitamin $\mathrm{A}$ (retinol) is essentially one-half of the $\beta$-carotene molecule. The average daily requirement recommended by the World Health Organization is $2.4-3.5 \mathrm{mg}$ for adults. The typical white-fleshed cassava genotypes largely used in Nigeria contain only small amounts of $\beta$-carotene [15]; however, yellow-fleshed cassava contains up to about 100 times as much [16]. Studies have been conducted on retention of $\beta$-carotene from cassava roots that had been boiled, ovendried, sun-dried, shadow-dried, or used for gari preparation. Oven-drying, shadow drying and boiling retained the highest levels of $\beta$-carotene $(71.9 \% ; 59.2 \%$ and $55.7 \%$ resp.) and gari the lowest (about 34.1\%) [17]. Increasing the consumption of yellow-fleshed cassava roots and their processed food products can provide a significant proportion of the required dietary vitamin A intake. It is therefore important to breed and promote the cassava varieties enriched with high levels of $\beta$-carotene to combat the widespread vitamin A deficiency in Nigeria.

\section{Materials and Methods}

This study was conducted at the advanced multilocation yield trial breeding stage (called uniform yield trial) with 21 yellow-fleshed cassava genotypes including two checks. The trial was run for two cropping seasons (2009-2010 and 2010-2011) at five locations representing the major cassava growing agroecological zones in Nigeria. The checks, TMS 01/1368 and TMS 01/1371, were improved yellowfleshed genotypes that were officially released in Nigeria in December 2011. The trial locations were Ibadan $\left(7^{\circ} 38^{\prime} \mathrm{N}\right.$, $3^{\circ} 89^{\prime} \mathrm{E}$; forest-savanna transition, 227 masl, annual rainfall $1312 \mathrm{~mm}$, annual average temperatures $20.3-33.8^{\circ} \mathrm{C}$; soil type Ferric Luvisols); Ikenne $\left(6^{\circ} 86^{\prime} \mathrm{N}, 3^{\circ} 71^{\prime} \mathrm{E}\right.$; humid forest, $44 \mathrm{masl}$, annual rainfall $1515 \mathrm{~mm}$, annual average temperatures $22.3-33.4^{\circ} \mathrm{C}$; soil type Dystric Nitosols); Ubiaja $\left(6^{\circ} 65^{\prime} \mathrm{N}, 6^{\circ} 38^{\prime} \mathrm{E}\right.$, subhumid forest, $287 \mathrm{masl}$, annual rainfall $1186 \mathrm{~mm}$, annual average temperatures $19.9-32.6^{\circ} \mathrm{C}$; soil type Dystric Nitosols); Mokwa $\left(9^{\circ} 28^{\prime} \mathrm{N}, 5^{\circ} 05^{\prime} \mathrm{E}\right.$, southern Guinea savanna, $132 \mathrm{masl}$, annual rainfall $1149 \mathrm{~mm}$, annual average temperatures $18.1-37.3^{\circ} \mathrm{C}$; soil type Dystric Nitosols); and Zaria $\left(11^{\circ} 16^{\prime} \mathrm{N}, 7^{\circ} 63^{\prime} \mathrm{E}\right.$; northern Guinea savanna, $687 \mathrm{masl}$, annual rainfall $1076 \mathrm{~mm}$, annual average temperatures $13.9-35.5^{\circ} \mathrm{C}$; soil type Ferric Luvisols). The five locations combined with the two cropping seasons constituted the 10 evaluation environments. The environments are coded in the graphics as follows: Ibadan 2009-2010 ( $\left.\mathrm{E}_{1}\right)$, 2010-2011 ( $\left.\mathrm{E}_{2}\right)$; Ikenne 2009-2010 ( $\left.\mathrm{E}_{3}\right), 2010-2011\left(\mathrm{E}_{4}\right)$; Ubiaja 2009-2010 (E $\left.\mathrm{E}_{5}\right), 2010-2011\left(\mathrm{E}_{6}\right)$; Mokwa 2009-2010 $\left(\mathrm{E}_{7}\right), 2010-2011\left(\mathrm{E}_{8}\right)$; and Zaria 2009-2010 (E9) and 2010$2011\left(\mathrm{E}_{10}\right)$. The graphic representations of the genotypes were $G_{1}$ to $G_{21}$. The cassava genotypes were grown for two 12-month cropping seasons under rainfed conditions in a randomized complete block design with four replications. Each plot was $6 \mathrm{~m}$ by $6 \mathrm{~m}$ consisting of 36 plants spaced $1 \mathrm{~m}$ apart in 6 rows on $30 \mathrm{~cm}$ ridges spaced $1 \mathrm{~m}$ apart. No fertilizer was applied. Weeds were controlled as necessary. Harvesting in all locations was at approximately 12 months after planting (MAP). A border of $1 \mathrm{~m}$ was left and only the inner plants (maximum of 16 per plot) were harvested. The severity of cassava mosaic disease (CMD) was scored using the scale 1 to 5 system described by IITA [18] $(1=$ no symptom and $5=$ severe symptoms). An average CMD severity was calculated based on ratings taken at 1, 3, and 6 MAP. Root fresh yield/ha was calculated based on the weight of roots of inner plants harvested/plot. The root dry matter content (DMC) was determined for each genotype from a random sample of three roots/plot from only two replications. To determine the dry matter percentage, a $100 \mathrm{~g}$ sample (taken after the three roots had been washed and shredded) was oven-dried at $70^{\circ} \mathrm{C}$ for $48 \mathrm{hr}$. The percentage of DMC was calculated as the ratio of the dry weight multiplied by 100 over the fresh weight as indicated below:

$$
\mathrm{DMC}=\frac{\text { Sample dry weight } \times 100}{\text { Sample fresh weight }} .
$$

The dry root yield (DYLD) is the product of the fresh root yield (FYLD) multiplied by the percentage of the DMC:

$$
\mathrm{DYLD}=\mathrm{FYLD} \times \mathrm{DMC} .
$$

For laboratory determinations of total carotene concentration (TCC), five medium sized roots were collected from the harvested roots in two replications. Three of the five roots were washed dried, peeled, and again washed and dried. Each peeled root was cut longitudinally in half and the halves were again cut longitudinally into quarters. Two opposite quarters of the three roots were pooled for total carotene quantification. The six quarters were cut in small pieces of about $1 \mathrm{~cm}^{3}$ and mixed together. After many subdivisions, a sample of approximately 10-15 g of small pieces of root was taken as a uniform and representative sample and ground in refrigerated acetone solvent using a mortar and pestle. During sample preparation, special care was taken to avoid directly exposing the storage roots to sunlight and the lights in the laboratory were protected with UV filters. Samples were covered with aluminum foil when not under processing. 
All the total carotene analyses were completed within $24 \mathrm{hr}$ after each harvest, using the spectrophotometer method described in the HarvestPlus handbook for Carotenoid Analysis [19] as follows. Twenty $\mathrm{ml}$ of petroleum ether $(\mathrm{PE})$ with low boiling point of $35-60^{\circ} \mathrm{C}$ (used as solvent in extraction or partition) is put in a $500 \mathrm{~mL}$ separatory funnel with Teflon stop-cock and add the acetone extract. Distilled water was slowly added $(\sim 300 \mathrm{~mL})$, flowing along the walls of the funnel to avoid formation of an emulsion. After adding the distilled water, two separated phases were identified. The two phases were allowed to separate and the lower aqueous-acetone phase discarded. This washing with distilled water was done 3 to 4 times to remove residual acetone. In the last washing, the totality of the lower phase was completely discarded. The PE phase was then collected in a volumetric flask through a small funnel containing anhydrous sodium sulphate to remove the residual water. The separatory funnel was washed with PE and the washing in the volumetric flask by passing through the funnel and the sodium sulphate. For spectrophotometer reading and calculation, it is important to make up to volume with $\mathrm{PE}$ and take the absorbance at $450 \mathrm{~nm}$. It may be necessary to concentrate or dilute the carotenoids solution so that the absorbance should be between 0.2 and 0.8. The total carotenoids concentration is calculated using the following formula:

$$
\operatorname{TCC}(\mu \mathrm{g} / \mathrm{g})=\frac{A \times \text { volume }(\mathrm{mL}) \times 10^{4}}{A_{1 \mathrm{~cm}}^{1 \%} \times \text { sample weight }(\mathrm{g})},
$$

where $A$ = absorbance, volume $=$ total volume of extract, and $A_{1 \mathrm{~cm}}^{1 \%}=$ absorption coefficient of $\beta$-carotene in PE (2592).

Data collected were statistically analyzed using analysis of variance and GGE biplot. "GGE biplot" is a data visualization tool that is based on principal component analysis (PCA) of environment-centered or standardized $\mathrm{G} \times \mathrm{E}$ data because these biplots display both genotype main effects $(G)$ and genotype by environment interactions (GE), which are the two sources of variation that are relevant to variety evaluation [20]. $\mathrm{G} \times \mathrm{E}$ data analysis includes three major aspects: (i) megaenvironment analysis (ii) test environment evaluation, and (iii) genotype evaluation [21, 22]. A GGE biplot is constructed by plotting the first principal component (PC1) scores of the genotypes and the environments against their respective PC2 scores resulted from the singular value decomposition (SVD) of environment-centered or standardized $\mathrm{G} \times \mathrm{E}$ data. The "which-won-where view" of the GGE biplot [23] is an effective tool in megaenvironment analysis. It consists of a polygon and a set of perpendicular lines to the sides of the polygon. The polygon is drawn on genotypes located farthest away from the biplot origin in various directions such that all genotypes are contained in it. The perpendicular lines are drawn from the biplot origin to divide the biplot into sectors. If all environments fall into a single sector, it means that a single genotype had the highest yield (performance) in all environments. If the environments fall into different sectors, it means that different genotypes won in different sectors.

\section{Results and Discussion}

Mean performance of the 21 yellow-fleshed cassava genotypes across the 10 environments are presented (Table 1). The lowest CMD score 1.0 was recorded for TMS 07/0539 $\left(\mathrm{G}_{10}\right)$ and TMS 07/0628 $\left(\mathrm{G}_{14}\right)$. The mean CMD was 2.0. The highest means for FYLD and DYLD were recorded by the check TMS 01/1368 and the overall averages across the environments were $10.6 \mathrm{tha}^{-1}$ (FYLD) and $2.3 \mathrm{tha}^{-1}$ (DYLD). The mean of DMC was $21.0 \%$ with the highest value recorded by the genotype TMS $07 / 0593\left(\mathrm{G}_{13}\right)$. The mean TCC was $7.8 \mu \mathrm{g} \mathrm{g}^{-1}$ and the genotype TMS 07/0593 had the highest average of $11.7 \mu \mathrm{gg}^{-1}$.

The combined analysis of variance tables showed for all traits that $\mathrm{G}, \mathrm{E}$, and $\mathrm{GE}$ were significant $(P<0.001)$.

3.1. Cassava Mosaic Disease. The average severity score of CMD of the 21 genotypes across the 10 environments was higher than the scoring results reported in similar studies conducted from 2004 to 2006 in Nigeria [24]. The combined analysis of variance of CMD scores of the 21 yellow-fleshed genotypes evaluated during 2 years in five locations showed significant differences $(P<0.001)$ among G, E, and GE. Genotypes TMS 07/0539 $\left(\mathrm{G}_{10}\right)$ and TMS 07/0628 $\left(\mathrm{G}_{14}\right)$ did not show any visible symptoms of CMD (score $=1.0)$ in any of the 10 environments and were grouped together with $G_{3}, G_{4}, G_{7}, G_{9}, G_{13}$, and $G_{16}$ which, on average, scored 1.1 (Table 1). On the contrary, genotypes $\mathrm{G}_{1}, \mathrm{G}_{5} ; \mathrm{G}_{6} \mathrm{G}_{8}, \mathrm{G}_{11}$, $G_{12}, G_{15}$, and $G_{17}$ showed severe CMD symptoms and had the highest severity scores across the 10 environments.

The combined analysis of variance of CMD revealed that $\mathrm{G}$ contributed $72.1 \%$ of the total sum of squares; $\mathrm{E}$ contributed $7.4 \%$ and GE $8.7 \%$ as per Table 2.

In the GGE biplot analysis, the PC1 (91.2\%) and PC2 $(2.7 \%)$ together explained $93.9 \%$ of the total variability attributed to $G$ and GE. A polygon view of the GGE biplot (Figure 1) showed which genotypes performed better or worse for CMD in which environments. The vertex genotypes for CMD severity were $G_{2}, G_{4}, G_{13}, G_{5}, G_{6}$, and $G_{17}$. Two megaenvironments were defined. The first megaenvironment included $\mathrm{E}_{2}, \mathrm{E}_{3}, \mathrm{E}_{5}$, and $\mathrm{E}_{6}$ with the winning niche occupied by genotypes $\mathrm{G}_{5}$ and $\mathrm{G}_{6}$. The second megaenvironment fell in the sector of genotype $G_{17}$ and comprised environments $\mathrm{E}_{1}, \mathrm{E}_{4}, \mathrm{E}_{7}, \mathrm{E}_{8}, \mathrm{E}_{9}$, and $\mathrm{E}_{10}$.

3.2. Fresh Storage Root Yield Per Hectare. Analysis of variance of the FYLD showed significant differences $(P<0.001)$ among G, E, and GE. The significant GE for FYLD indicated fluctuations in genotypic responses to different environments. FYLD is a trait that typically demonstrates high GE effects $[25,26]$. This was observed in the present study and emphasizes the importance of the multi-environment evaluations of newly developed varieties. The average yields of 7.0 to 17.9 tha $^{-1}$ of this study were lower than 11.5 to 25.1 tha $^{-1}$ observed in a similar study in Benin [27].

The combined analysis of variance for FYLD (Table 3) indicated that $\mathrm{G}$ accounted for $12.1 \%$ of the total sum of squares for FYLD; E contributed for $42.8 \%$ and $17.1 \%$ 
TABLe 1: Average CMD severity score, fresh root yield $\left(\right.$ tha $\left.^{-1}\right)$, root dry matter content (\%), root dry yield (tha ${ }^{-1}$ ), and total carotene concentration $\left(\mu \mathrm{g} \mathrm{g}^{-1}\right)$ of 21 yellow-fleshed cassava genotypes in 10 environments.

\begin{tabular}{|c|c|c|c|c|c|c|}
\hline Genotype & & $\mathrm{CMD}$ & FYLD $\left(\right.$ tha $\left.^{-1}\right)$ & DMC (\%) & DYLD $\left(\right.$ tha $\left.^{-1}\right)$ & $\operatorname{TCC}\left(\mu \mathrm{g} \mathrm{g}^{-1}\right)$ \\
\hline TMS $01 / 1368^{1}$ & $\mathrm{G}_{1}$ & $2.7^{\mathrm{ab}}$ & $17.9^{\mathrm{a}}$ & $22.7^{\mathrm{abc}}$ & $4.1^{\mathrm{a}}$ & $8^{\mathrm{bc}}$ \\
\hline TMS $01 / 1371^{1}$ & $\mathrm{G}_{2}$ & $1.7^{\mathrm{d}}$ & $12.6^{\mathrm{abc}}$ & $20.9^{\mathrm{abcd}}$ & $2.8^{\mathrm{ab}}$ & $6.9^{c}$ \\
\hline TMS 06/0889 & $\mathrm{G}_{3}$ & $1.1^{\mathrm{e}}$ & $7.8^{\mathrm{cd}}$ & $16.1^{\mathrm{d}}$ & $1.2^{\mathrm{c}}$ & $7.0^{c}$ \\
\hline TMS 06/1635 & $\mathrm{G}_{4}$ & $1.1^{\mathrm{e}}$ & $10.1^{\mathrm{bc}}$ & $22.1^{\mathrm{abc}}$ & $2.4^{\mathrm{b}}$ & $8.8^{\mathrm{bc}}$ \\
\hline TMS 07/0481 & $\mathrm{G}_{5}$ & $2.9^{\mathrm{ab}}$ & $11.2^{\mathrm{bc}}$ & $22.3^{\mathrm{abc}}$ & $2.7^{\mathrm{ab}}$ & $6.4^{\mathrm{c}}$ \\
\hline TMS 07/0498 & $\mathrm{G}_{6}$ & $3.2^{\mathrm{a}}$ & $8.5^{\mathrm{cd}}$ & $22.1^{\mathrm{abc}}$ & $1.9^{\mathrm{bc}}$ & $6.3^{c}$ \\
\hline TMS 07/0520 & $\mathrm{G}_{7}$ & $1.1^{\mathrm{e}}$ & $12.5^{\mathrm{abc}}$ & $18.0^{\mathrm{cd}}$ & $2.4^{\mathrm{b}}$ & $7.6^{\mathrm{bc}}$ \\
\hline TMS 07/0525 & $\mathrm{G}_{8}$ & $2.8^{\mathrm{ab}}$ & $10.5^{\mathrm{bc}}$ & $20.6^{\mathrm{abcd}}$ & $2.1^{\mathrm{bc}}$ & $6.7^{\mathrm{c}}$ \\
\hline TMS 07/0534 & $\mathrm{G}_{9}$ & $1.1^{\mathrm{e}}$ & $8.9^{\mathrm{cd}}$ & $24.0^{\mathrm{a}}$ & $2.9^{\mathrm{ab}}$ & $7.0^{c}$ \\
\hline TMS 07/0539 & $\mathrm{G}_{10}$ & $1.0^{\mathrm{e}}$ & $11.8^{\mathrm{abc}}$ & $20.1^{\mathrm{abcd}}$ & $2.4^{\mathrm{b}}$ & $8.7^{\mathrm{bc}}$ \\
\hline TMS 07/0553 & $\mathrm{G}_{11}$ & $2.9^{\mathrm{ab}}$ & $15.5^{\mathrm{ab}}$ & $20.3^{\mathrm{abcd}}$ & $3.3^{\mathrm{ab}}$ & $7.6^{\mathrm{bc}}$ \\
\hline TMS 07/0576 & $\mathrm{G}_{12}$ & $3.1^{\mathrm{a}}$ & $8.9^{\mathrm{cd}}$ & $19.9^{\mathrm{abcd}}$ & $1.6^{\mathrm{c}}$ & $7.9^{\mathrm{bc}}$ \\
\hline TMS 07/0593 & $\mathrm{G}_{13}$ & $1.1^{\mathrm{e}}$ & $10.6^{\mathrm{bc}}$ & $24.3^{\mathrm{a}}$ & $2.8^{\mathrm{ab}}$ & $11.7^{\mathrm{a}}$ \\
\hline TMS 07/0628 & $\mathrm{G}_{14}$ & $1.0^{\mathrm{e}}$ & $8.2^{\mathrm{cd}}$ & $20.1^{\mathrm{abcd}}$ & $1.8^{\mathrm{bc}}$ & $7.1^{\mathrm{c}}$ \\
\hline TMS 07/0632 & $\mathrm{G}_{15}$ & $3.3^{\mathrm{a}}$ & $10.6^{\mathrm{bc}}$ & $17.9^{\mathrm{cd}}$ & $1.8^{\mathrm{bc}}$ & $6.8^{c}$ \\
\hline TMS 07/0749 & $\mathrm{G}_{16}$ & $1.1^{\mathrm{e}}$ & $12.2^{\mathrm{abc}}$ & $23.4^{\mathrm{ab}}$ & $2.8^{\mathrm{ab}}$ & $7.7^{\mathrm{b}}$ \\
\hline TMS 07/0824 & $\mathrm{G}_{17}$ & $3.3^{\mathrm{a}}$ & $10.3^{\mathrm{bc}}$ & $19.5^{\mathrm{abcd}}$ & $1.9^{\mathrm{bc}}$ & $8.8^{\mathrm{b}}$ \\
\hline TMS 07/0874 & $\mathrm{G}_{18}$ & $1.6^{\mathrm{d}}$ & $7.0^{\mathrm{cd}}$ & $20.5^{\mathrm{abcd}}$ & $1.7^{\mathrm{c}}$ & $6.7^{c}$ \\
\hline TMS 07/0952 & $\mathrm{G}_{19}$ & $1.9^{\mathrm{cd}}$ & $3.5^{\mathrm{d}}$ & $18.7^{\mathrm{bcd}}$ & $0.8^{c}$ & $9.2^{\mathrm{b}}$ \\
\hline TMS 07/0962 & $\mathrm{G}_{20}$ & $2.4^{\mathrm{bc}}$ & $9.6^{\mathrm{bcd}}$ & $19.4^{\mathrm{abcd}}$ & $1.8^{\mathrm{bc}}$ & $6.5^{\mathrm{c}}$ \\
\hline TMS 07/0999 & $\mathrm{G}_{21}$ & $2.4^{\mathrm{bc}}$ & $7.8^{\mathrm{cd}}$ & $19.7^{\text {abcd }}$ & $1.9^{\mathrm{bc}}$ & $7.9^{\mathrm{bc}}$ \\
\hline Mean & & 2.0 & 10.6 & 21.0 & 2.3 & 7.8 \\
\hline SE & & 0.4 & 4.5 & 3.5 & 1.1 & 1.3 \\
\hline $\mathrm{CV} \%$ & & 20.2 & 42.1 & 16.8 & 47.9 & 17.3 \\
\hline
\end{tabular}

${ }^{1}$ : genotypes used as checks.

Means with the same letter in a column are not significantly different at $95 \%$ level.

TABle 2: Combined analysis of variance table of genotype, environment, and genotype by environment contributions to the sum of squares of CMD severity of 21 yellow-fleshed genotypes in 10 environments.

\begin{tabular}{lcccccc}
\hline \multicolumn{7}{c}{ Cassava mosaic disease (CMD) } \\
Source & DF & SS & MS & $F$ & $P$ & \% Total SS \\
\hline Total & 776 & 867.1 & & & & \\
Genotype & 20 & 625.6 & 31.3 & 187.1 & $<0.001$ & 72.1 \\
Environment & 9 & 63.7 & 7.1 & 42.4 & $<0.001$ & 7.4 \\
GE & 170 & 75.8 & 0.4 & 2.7 & $<0.001$ & 8.7 \\
BLK (ENV) & 30 & 10.5 & 0.3 & 2.1 & & \\
Error & 547 & 91.5 & 0.2 & & & \\
\hline
\end{tabular}

was attributed to GE. In the GGE biplot analysis, PC1 and PC2 explained together $80.5 \%$ of the total variation and graphically summarized genotype performance in relation to the environments evaluated in the study. A polygon view of the GGE biplot (Figure 2) shows which genotypes performed best or worst in which environments for FYLD. The vertex genotypes were $G_{1}, G_{11}, G_{19}$, and $G_{6}$. The other genotypes were located within the polygon and were found less responsive. The megaenvironment made up of $\mathrm{E}_{3}, \mathrm{E}_{4}$, $\mathrm{E}_{5}, \mathrm{E}_{6}, \mathrm{E}_{7}, \mathrm{E}_{8}, \mathrm{E}_{9}$, and $\mathrm{E}_{10}$ fell in the niche where genotype
TABle 3: Combined analysis of variance table of genotype, environment, and genotype by environment contributions to the sum of squares of fresh root yield of 21 yellow-fleshed genotypes in 10 environments.

\begin{tabular}{lcccccc}
\hline \multicolumn{7}{c}{ Fresh Root Yield (FYLD) } \\
Source & DF & SS & MS & $F$ & $P$ & \% Total SS \\
\hline Total & 756 & 47344.3 & & & & \\
Genotype & 20 & 5750.1 & 287.5 & 14.3 & $<0.001$ & 12.1 \\
Environment & 9 & 20274.6 & 2252.7 & 111.9 & $<0.001$ & 42.8 \\
GE & 169 & 8116.4 & 48 & 2.4 & $<0.001$ & 17.1 \\
BLK (ENV) & 30 & 2569.7 & 85.7 & 4.2 & & \\
Error & 528 & 10633.5 & 20.1 & & & \\
\hline
\end{tabular}

TMS 01/1368 $\left(\mathrm{G}_{1}\right)$ used as check was the best performer. The second megaenvironment, $\mathrm{E}_{1}$ and $\mathrm{E}_{2}$, fell in the sector where genotype $\mathrm{G}_{11}$ was the best.

3.3. Root Dry Matter Content. The combined analysis of variance for root DMC of the 21 yellow-fleshed cassava genotypes showed significant differences $(P<0.001)$ among $\mathrm{G}, \mathrm{E}$, and GE. The mean root DMC ranged from 16.1 to $24.3 \%$ with an average of $21.0 \%$. These results are lower than those reported in earlier studies of yellow-fleshed genotypes 


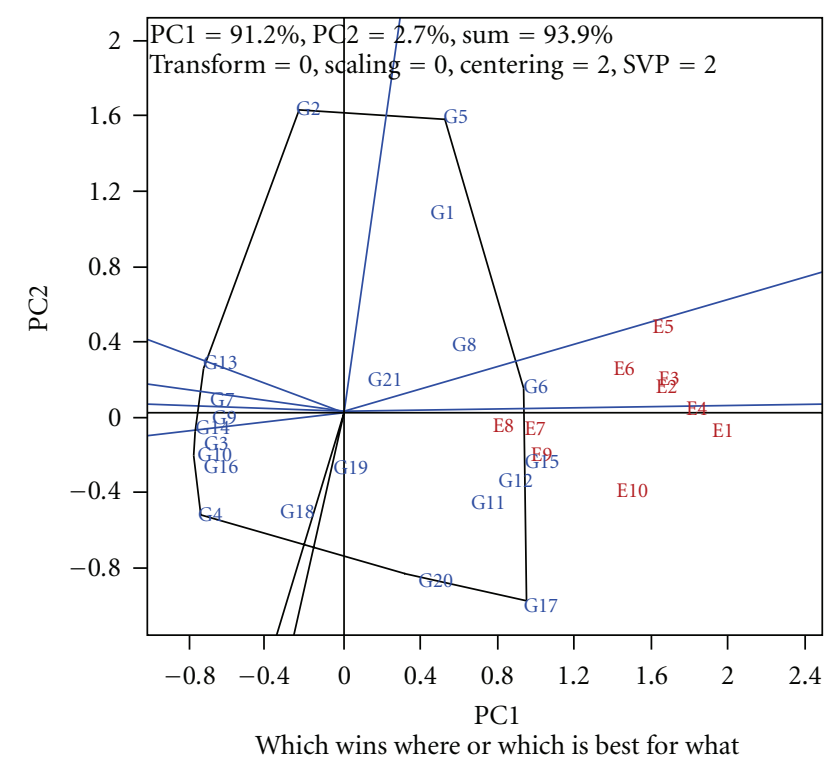

Figure 1: Megaenvironment defined by different winning yellowfleshed cassava genotypes tested in 10 environments for the average severity score of CMD.

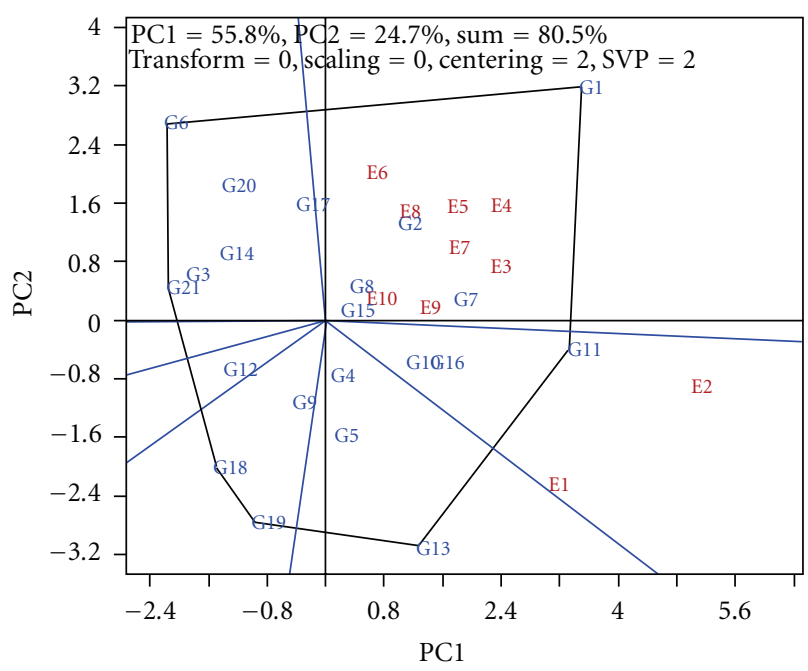

Which wins where or which is best for what

FIGURe 2: Megaenvironments defined by different winning yellowfleshed cassava genotypes tested in 10 environments for the average FYLD $\left(\right.$ tha $\left.^{-1}\right)$.

in Nigeria [28]. The highest DMC of $24.3 \%$ was obtained for the genotype TMS $07 / 0593\left(\mathrm{G}_{13}\right)$ followed by $\mathrm{G}_{9}(24.0 \%)$ and $\mathrm{G}_{16}(23.4 \%)$. G accounted for $23.8 \%$ to the total sum of squares variation for DMC, $42.3 \%$ of the total sum of squares were attributed to E, and $19.1 \%$ to GE (Table 4).

For the GGE biplot analysis, PC1 and PC2 together explained $68.3 \%$ of the total variation (Figure 3 ). The polygon view of the GGE biplot of DMC showed which genotypes performed best or worst in which environment. The vertex genotypes for DMC were $G_{3}, G_{6}, G_{13}, G_{9}$, and $\mathrm{G}_{12}$. According to the biplot, three megaenvironments were defined. The first was the winning niche of genotype $\mathrm{G}_{9}$
TABLE 4: Combined analysis of variance table of genotype, environment, and genotype by environment contributions to the sum of squares of dry matter content of 21 yellow-fleshed genotypes in 10 environments.

\begin{tabular}{lcccccc}
\hline \multicolumn{7}{c}{ Dry Matter Content (DMC) } \\
Source & DF & SS & MS & $F$ & $P$ & \% Total SS \\
\hline Total & 574 & 13648.1 & & & & \\
Genotype & 20 & 2269.4 & 113.5 & 9.1 & $<0.001$ & 16.6 \\
Environment & 9 & 3986.8 & 443 & 35.4 & $<0.001$ & 29.2 \\
GE & 167 & 2532.8 & 15.2 & 1.2 & $<0.001$ & 18.6 \\
BLK (ENV) & 20 & 376.8 & 18.8 & 1.5 & & \\
Error & 358 & 4482.4 & 12.5 & & & \\
\hline
\end{tabular}

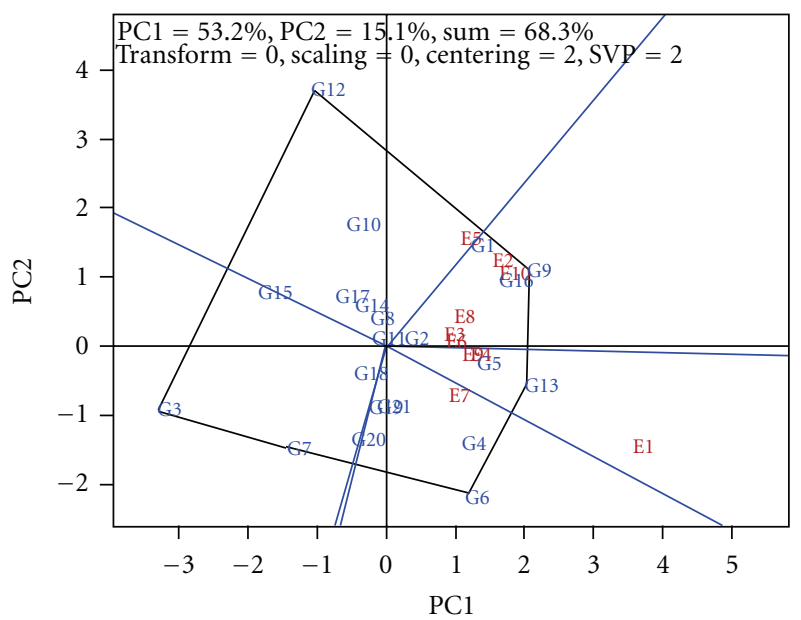

Which wins where or which is best for what

FIGURE 3: Megaenvironments defined by different winning yellowfleshed cassava genotypes tested in 10 environments for the average root $\mathrm{DMC}(\%)$.

made of $E_{2}, E_{3}, E_{6}, E_{8}$, and $E_{10}$. The second fell in the sector with genotype $G_{13}$ made of environments $E_{1}, E_{4}, E_{7}$, and $E_{9}$, and the third was led by genotype $G_{12}$ and made of environment $\mathrm{E}_{5}$.

3.4. Root Dry Yield (DYLD). Combined analysis of variance of DYLD revealed significant differences $(P<0.001)$ for $G$, $\mathrm{E}$, and GE. The average DYLD of the 21 genotypes across the 10 environments ranged from 0.8 to 4.1 tha $^{-1}$. The highest average DYLD (4.1 tha ${ }^{-1}$ ) was recorded by the check TMS $01 / 1368\left(G_{1}\right)$. The overall average DYLD was $2.3 \mathrm{tha}^{-1}$. These results were lower than those reported in [24] on 25 yellowfleshed genotypes in Nigeria.

The combined analysis of variance (Table 5) for DYLD indicated that $13.6 \%$ of the variation of the total sum of squares was contributed by $\mathrm{G}, 39.6 \%$ by $\mathrm{E}$ and $23.0 \%$ was due to GE.

In GGE biplot analysis PC1 and PC2 explained together $77.3 \%$ of the total variation. Figure 4 summarizes the relative performance of each genotype and shows which genotypes performed best or worst in which environments for DYLD. The vertex genotypes were $G_{1}, G_{3}$, and $G_{9}$. One of the 
TABLE 5: Combined analysis of variance table of genotype, environment, and genotype by environment contributions to the sum of squares of root dry yield of 21 yellow-fleshed genotypes in 10 environments.

\begin{tabular}{lcccccc}
\hline \multicolumn{7}{c}{ Root dry yield (DYLD) } \\
Source & DF & SS & MS & $F$ & $P$ & \% Total SS \\
\hline Total & 571 & 2085 & & & & \\
Genotype & 20 & 283.1 & 14.1 & 11.6 & $<0.001$ & 13.6 \\
Environment & 9 & 826.6 & 91.8 & 74.9 & $<0.001$ & 39.6 \\
GE & 166 & 479.7 & 2.9 & 2.3 & $<0.001$ & 23.0 \\
BLK (ENV) & 20 & 59.3 & 3 & 2.4 & & \\
Error & 356 & 436.3 & 1.2 & & & \\
\hline
\end{tabular}

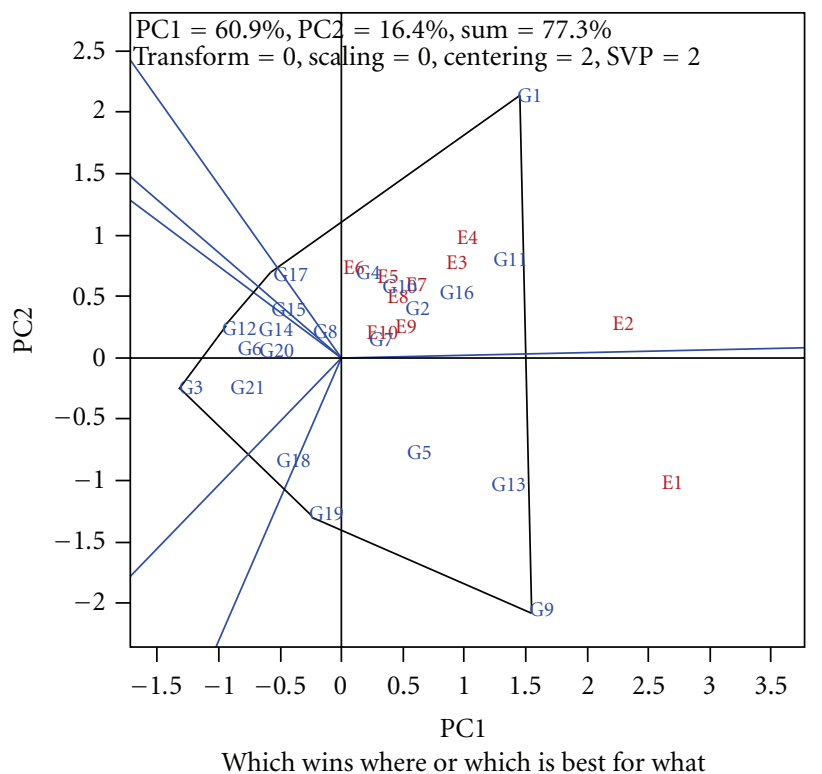

Figure 4: Megaenvironments defined by different winning yellowfleshed cassava genotypes tested in 10 environments for the average $\operatorname{DYLD}\left(\mathrm{tha}^{-1}\right)$.

genotypes used as check, TMS $01 / 1368\left(\mathrm{G}_{1}\right)$, was the vertex genotype of a megaenvironment made up of 9 out of 10 environments $\left(E_{2}\right.$ to $\left.E_{10}\right)$. The remaining environment $\left(E_{1}\right)$ was the niche of genotype TMS 07/0534 $\left(\mathrm{G}_{9}\right)$.

3.5. Total Carotene Concentration in Fresh Storage Root (TCC). The combined statistical analysis of TCC recorded for the 21 yellow-fleshed cassava genotypes showed significant differences among G, E, and GE. The average TCC recorded ranged from 6.3 to $11.7 \mu \mathrm{g} \mathrm{g}^{-1}$ fresh weight. These TCC values were higher than the range of 1.4 to $7.7 \mu \mathrm{g} \mathrm{g}^{-1}$ obtained in a similar study conducted in Ghana [29]. The overall average of TCC of this study $\left(7.8 \mu \mathrm{g} \mathrm{g}^{-1}\right)$ was also higher than the $4.8 \mu \mathrm{g} \mathrm{g}^{-1}$ reported in 2007 for 25 yellowfleshed genotypes in Nigeria [30].

The best genotype for TCC was TMS 07/0593 $\left(\mathrm{G}_{13}\right)$ (Table 1). For TCC, G contributed $34.4 \%$ to the variation of the total sum of squares, E contributed $11.3 \%$, and GE contributed $25.6 \%$ as per Table 6 .
TABLE 6: Combined analysis of variance table of genotype, environment, and genotype by environment contributions to the sum of squares of total carotene concentration of 21 yellow-fleshed genotypes in 10 environments.

\begin{tabular}{lcccccc}
\hline \multicolumn{7}{c}{ Total carotene concentration (TCC) } \\
Source & DF & SS & MS & $F$ & $P$ & \% Total SS \\
\hline Total & 542 & 2186 & & & & \\
Genotype & 20 & 752.3 & 37.6 & 20.8 & $<0.001$ & 34.4 \\
Environment & 9 & 247.5 & 27.5 & 15.2 & $<0.001$ & 11.3 \\
GE & 167 & 559.6 & 3.4 & 1.8 & $<0.001$ & 25.6 \\
BLK (ENV) & 18 & 32.1 & 1.8 & 1 & & \\
Error & 328 & 594.4 & 1.8 & & & \\
\hline
\end{tabular}

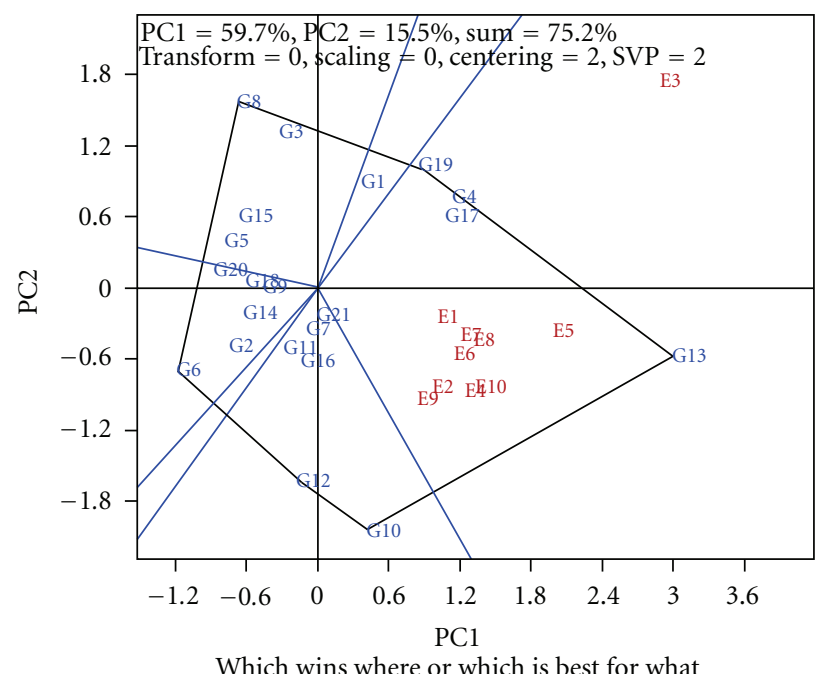

Figure 5: Mega-environment defined by different winning yellowfleshed cassava genotypes tested in 10 environments for average TCC $\left(\mu \mathrm{gg}^{-1}\right)$.

In the GGE biplot analysis of TCC, the PC1 and PC2 together explained $75.2 \%$ of the total variation. The polygon view of the GGE biplot of TCC (Figure 5) showed which genotypes performed best or worst in which environments. The vertex genotypes for TCC were $\mathrm{G}_{13}, \mathrm{G}_{10}, \mathrm{G}_{6}$, and $\mathrm{G}_{8}$. The genotype TMS 07/0593 $\left(\mathrm{G}_{13}\right)$ that had the highest average TCC was the best in each of the 10 environments.

\section{Conclusion}

The combined analyses of datasets of the five traits (CMD, FYLD, DMC, DYLD, and TCC) of the 21 genotypes in 10 environments showed significant differences $(P<0.001)$ among G, E, and GE. With respect to each trait studied, genotypes showed differences in performance in specific environment. Considering FYLD and DYLD, the two checks TMS 01/1368 and TMS 01/1371, together with TMS 07/0553 and TMS 07/0749 have the highest performance for FYLD and DYLD. For reaction to CMD, eight genotypes (TMS 07/0539, TMS 07/0628, TMS 06/0889, TMS 06/1635, TMS 07/0520, TMS 07/0534, TMS 07/0593, and TMS 07/0749) 
showed very few or no symptoms in the 10 environments. For percentage DMC, 17 genotypes were grouped in the first category led by TMS 07/0593 and TMS 07/0534 with the highest DMC. The highest TCC was recorded by the genotype TMS 07/0593. From the results of this study, TMS 07/0593 showed outstanding performance for TCC and good performance for most other traits. It appeared to be the best genotype for food technologists and nutritionists to use for feeding trials to combat vitamin A deficiency. It will be a very good source for breeders to improve carotene concentration and resistance to CMD in yellow-fleshed cassava varieties.

\section{Acknowledgment}

The authors are grateful to HarvestPlus for financial support of these research findings.

\section{References}

[1] World Health Organization, Global Prevalence of Vitamin A Deficiency, WHO/NUT/95.3, Geneva, Switzerland, 1995.

[2] World Health Organization, "Control of Vitamin A deficiency and xerophthalmia," Tech. Rep. 672, Geneva, Switzerland, 1982.

[3] H. E. Cuevas, H. Song, J. E. Staub, and P. W. Simon, "Inheritance of beta-carotene-associated flesh color in cucumber (Cucumis sativus L.) fruit," Euphytica, vol. 171, no. 3, pp. 301$311,2010$.

[4] B. B. Maziya-Dixon, I. O. Akinyele, R. A. Sanusi, T. E. Oguntona, S. K. Nokoe, and E. W. Harris, "Vitamin A deficiency is prevalent in children less than 5 y of age in Nigeria," Journal of Nutrition, vol. 136, no. 8, pp. 2255-2261, 2006.

[5] F. Nweke, D. S. C. Spencer, and J. K. Lynam, The Cassava Transformation, Africa's best kept secret, Michigan State University Press, East Lansing, Mich, USA, 2002, Shaffi B., Mahler K. A., Price W. J., Auld D. L.

[6] H. Ceballos, T. Sánchez, A. L. Chávez et al., "Variation in crude protein content in cassava (Manihot esculenta Crantz) roots," Journal of Food Composition and Analysis, vol. 19, no. 6-7, pp. 589-593, 2006.

[7] FAO, Cassava Production Outlook, FAO, Rome, Italy, 2011.

[8] S. A. Eberhart and W. A. Russel, "Stability parameters for comparing varieties," Crop Science, vol. 6, pp. 36-40, 1966.

[9] M. S. Kang and R. Magari, "New developments in selecting for phenotypic stability in crop breeding," in Genotype-byEnvironment Interaction, M. S. Kang and H. G. Zobel Jr., Eds., pp. 51-84, CRC Press, Boca Raton, Fla, USA, 1996.

[10] D. B. Rodriguez-Amaya, "Nature and distribution of carotenoids in foods," in Shelf-Life Studies of Foods and Beverages. Chemical, Biological, Physical and Nutritional Aspects, G. Charalambous, Ed., pp. 547-589, Elsevier Science Publishers, Amsterdam, The Netherlands, 1993.

[11] D. B. Rodriguez-Amaya and M. Kimura, A Guide to Carotenoid Analysis in Foods, OMRI Research, International Life Sciences Institute (ILSI), Washington, DC, USA, 2001.

[12] S. R. A. Adewusi and J. H. Bradbury, "Carotenoids in cassava: comparison of open-column and HPLC methods of analysis," Journal of the Science of Food and Agriculture, vol. 62, no. 4, pp. 375-383, 1993.
[13] N. Nassar, C. S. Vizzotto, C. A. Schwartz, and O. R. Pires, "Cassava diversity in Brazil: the case of carotenoid-rich landraces," Journal Genetics and Molecular Research, vol. 6, no. 1, pp. 116-121, 2007.

[14] N. I. Krinsky, "The biological properties of carotenoids," Pure and Applied Chemistry, vol. 66, pp. 1003-1010, 1994.

[15] J. H. Bradbury and W. D. Holloway, Chemistry of Tropical Root Crops. Significance for Nutrition and Agriculture in the Pacific, Australian Centre for International Agricultural Research (ACIAR), Canberra, Australia, 1988.

[16] I. McDowell and K. A. Oduro, "Investigation of â-carotene content of yellow varieties of cassava (Manihot esculenta Crantz)," Journal of Plant Foods, vol. 5, pp. 169-171, 1983.

[17] A. L. Chávez, T. Sánchez, H. Ceballos et al., "Retention of carotenoids in cassava roots submitted to different processing methods," Journal of the Science of Food and Agriculture, vol. 87, no. 3, pp. 388-393, 2007.

[18] IITA, Cassava in Tropical Africa: A Reference Manual, International Institute of Tropical Agriculture, Ibadan, Nigeria, 1990.

[19] D. B. Rodriguez-Amaya and M. Kimura, HarvestPlus Handbook for Carotenoid Analysis, vol. 2 of HarvestPlus Technical Monograph, 2004.

[20] H. G. Gauch and R. W. Zobel, "AMMI analysis of yield trials," in Genotype by Environment Interaction, M. S. Kang and H. G. Gauch Jr., Eds., CRS Press, International Food Policy Research Institute (IFPRI) and International Center for Tropical Agriculture (CIAT), New York, NY, USA, 1996.

[21] W. Yan and M. S. Kang, GGE Biplot Analysis: A Graphical Tool for Breeders, Geneticists, and Agronomists, CRC Press, Boca Raton, Fla, USA, 2003.

[22] W. Yan and N. A. Tinker, "Biplot analysis of multi-environment trial data: principles and applications," Canadian Journal of Plant Science, vol. 86, no. 3, pp. 623-645, 2006.

[23] W. Yan, L. A. Hunt, Q. Sheng, and Z. Szlavnics, "Cultivar evaluation and mega-environment investigation based on the GGE biplot," Crop Science, vol. 40, no. 3, pp. 597-605, 2000.

[24] S. Gorrettie and D. Alfred, "Genotype $\times$ environment interaction, stability and agronomic performance of carotenoid-rich cassava clones," Scientific Research and Essays, vol. 2, no. 9, pp. 390-399, 2007.

[25] R. E. C. Mba and A. G. O. Dixon, "Genotype $\times$ environment interaction, phenotypic stability of cassava yields and heritability estimates for production and pests resistance traits in Nigeria," in Root Crops and Poverty Alleviation: Proceedings of the Sixth Triennial Symposium of the International Society for Tropical Root Crops-Africa Branch Held from 22 to 28 October 1995 in Lilongwe, Malawi, M. O. Akoroda and I. J. Ekanayake, Eds., pp. 255-261, 1998.

[26] C. N. Egesi, P. Ilona, F. O. Ogbe, M. Akoroda, and A. Dixon, "Genetic variation and genotype $\times$ environment interaction for yield and other agronomic traits in cassava in Nigeria," Agronomy Journal, vol. 99, no. 4, pp. 1137-1142, 2007.

[27] N. G. Maroya and A. G. O. Dixon, "Utilisation des paramètres de stabilité dans la sélection des clones de manioc pour le rendement en racine," in Root Crops For Food Security in Africa: Proceedings of the 5th Symposium of ISTRC-AB Held in Kampala, Uganda 22-28 November 1992, M. O. Akoroda, Ed., pp. 111-115, 1994.

[28] IITA (International Institute of Tropical Agriculture), Annual Report of Root, Tuber and Plantain Improvement Program, IITA, Ibadan, Nigeria, 1987. 
[29] N. G. Maroya, Genotype by environment interaction effect on beta carotene and some yield components of yellow root cassava (Manihot esculenta crantz) genotypes in Ghana [Ph.D. thesis], University of Ghana, Ghana, Legon, 2008.

[30] G. Ssemakula, A. G. O. Dixon, and B. Maziya-Dixon, "Stability of total carotenoid concentration and fresh yield of selected yellow-fleshed cassava (Manihot esculenta Crantz)," Journal of Tropical Agriculture, vol. 45, no. 1-2, pp. 14-20, 2007. 


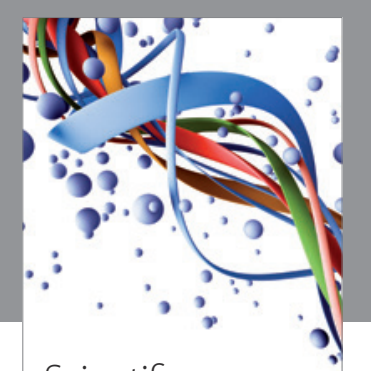

Scientifica
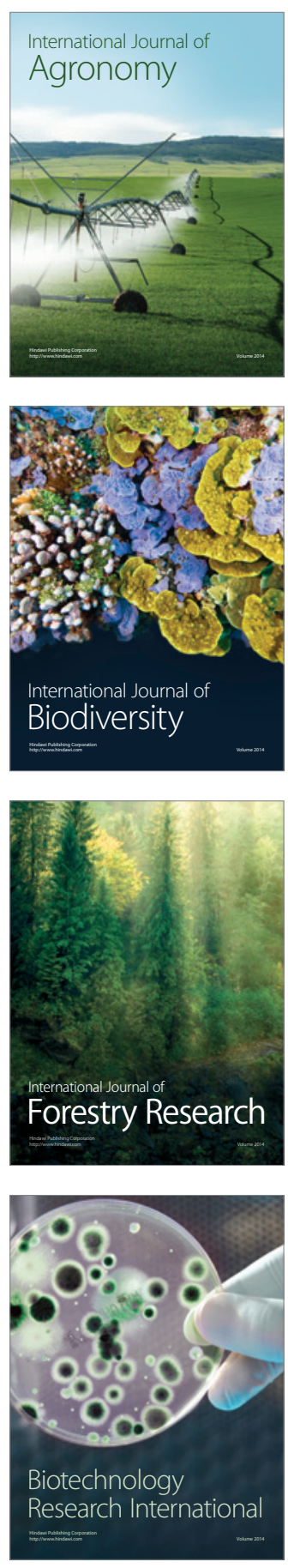
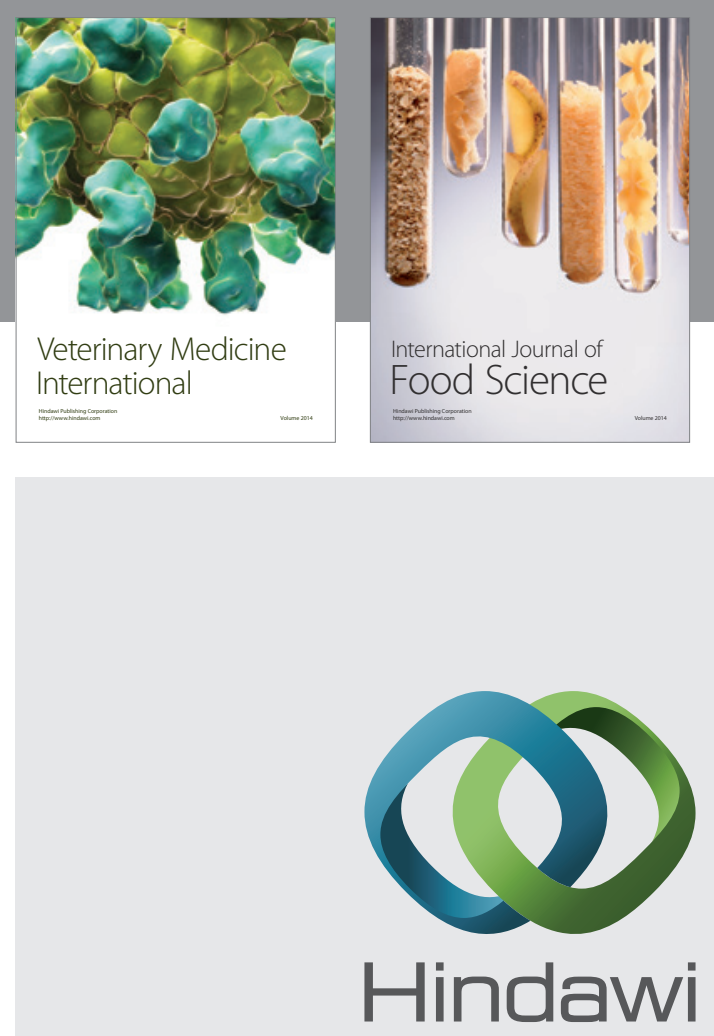

Submit your manuscripts at

http://www.hindawi.com
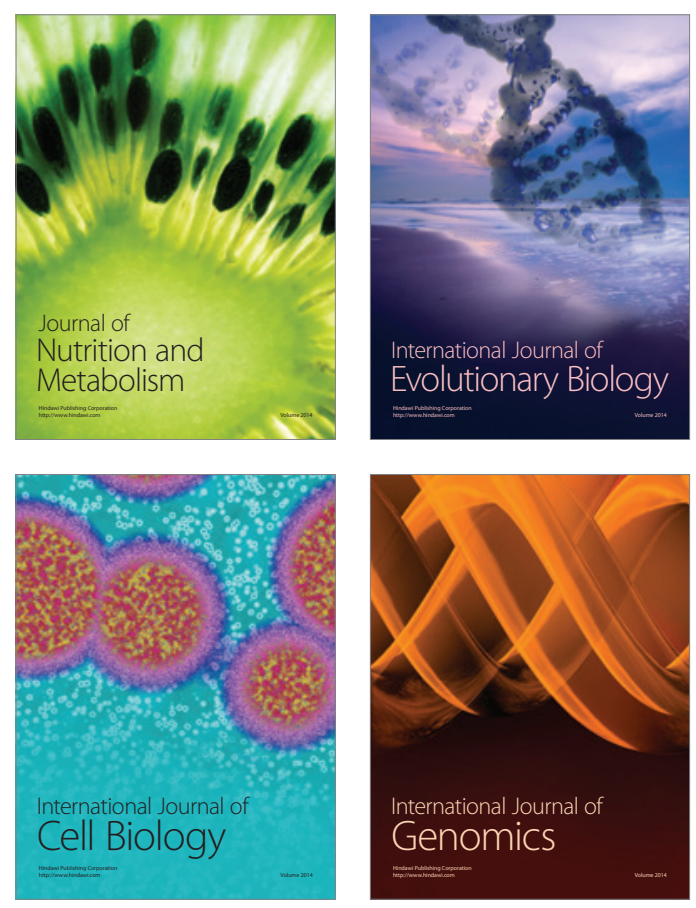
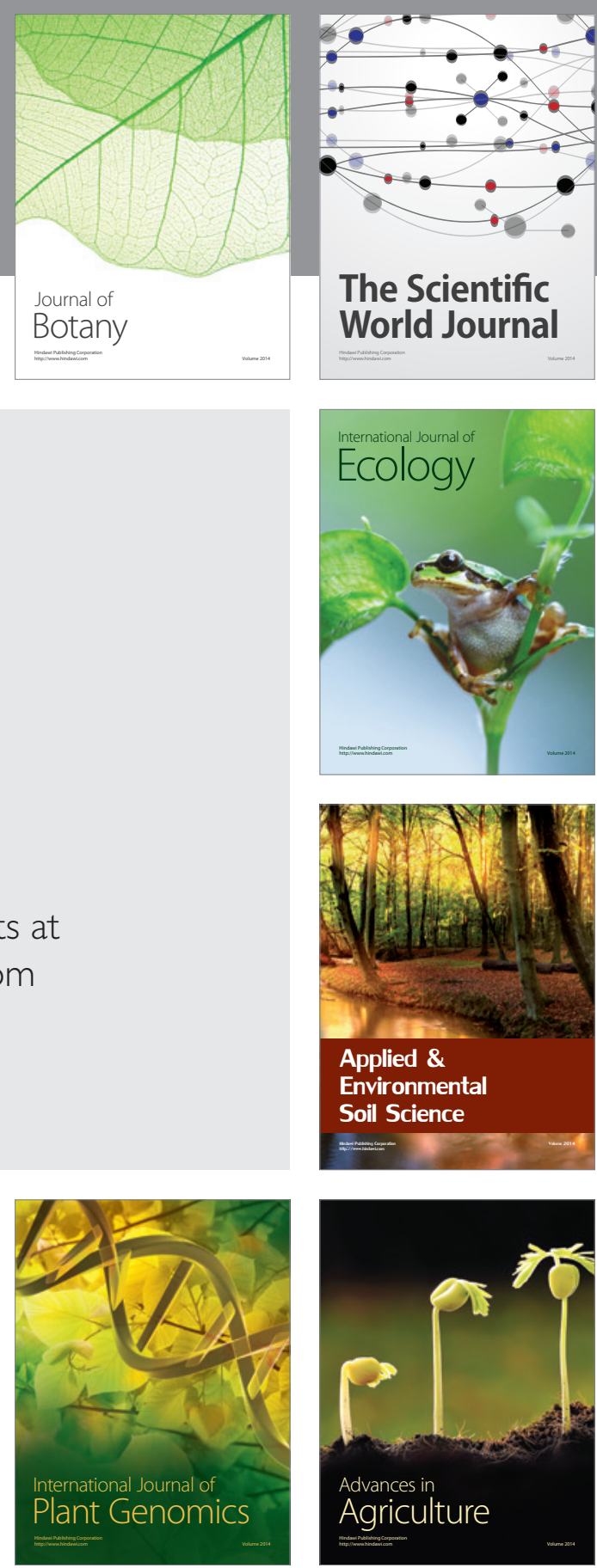

The Scientific World Journal
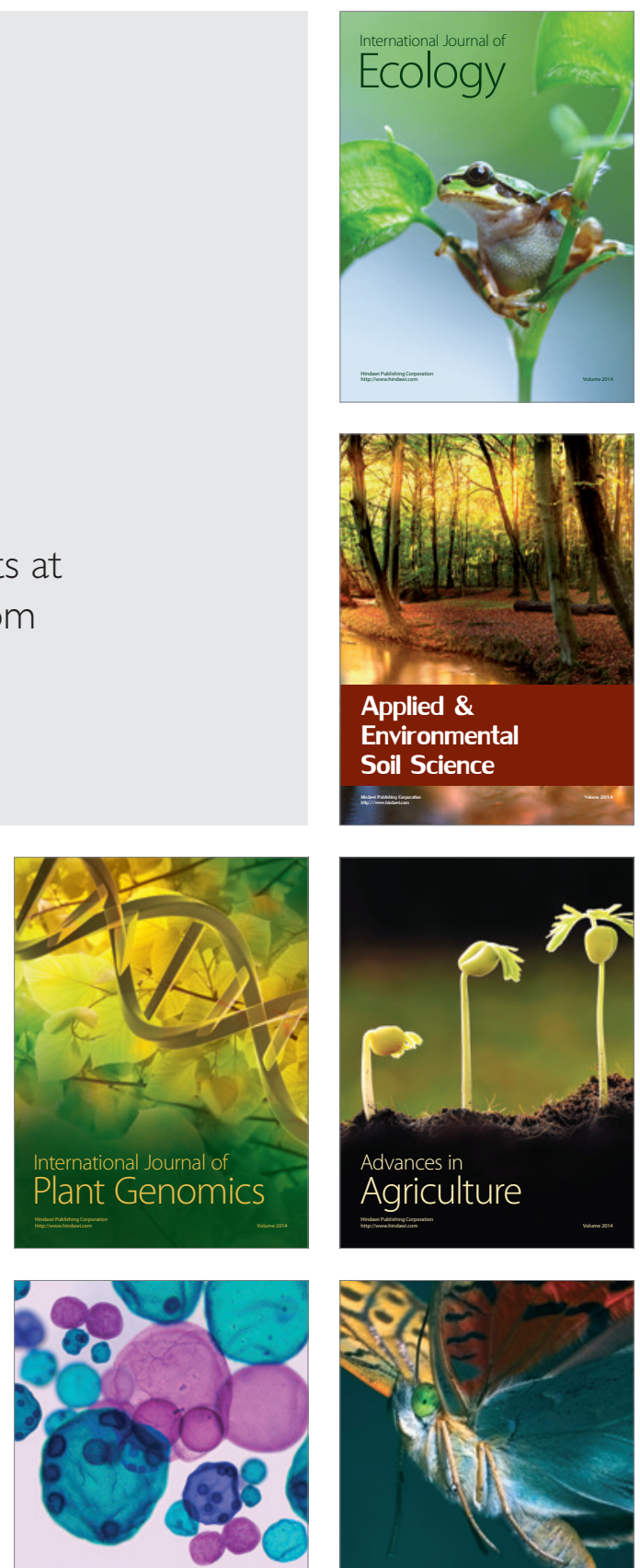

International Journal of Microbiology

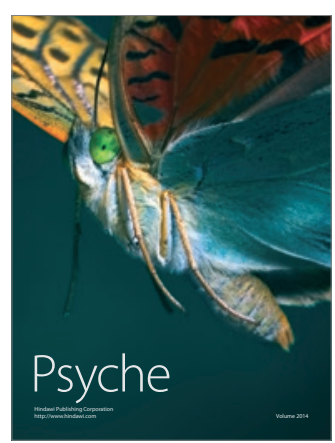

